\title{
Fournier's gangrene of the penis caused by Streptococcus dysgalactiae subspecies equisimilis: case report and incidence study in a tertiary-care hospital
}

\author{
Ram V Anantha ${ }^{1,2^{*}}$, Katherine J Kasper ${ }^{1}$, Kelcey G Patterson ${ }^{1}$, Joseph J Zeppa ${ }^{1}$, Johan Delport ${ }^{1}$
} and John K McCormick ${ }^{1}$

\begin{abstract}
Background: Fournier's gangrene is a rare necrotizing soft tissue infection of the scrotum and penis. We report, to our knowledge, the first case of Fournier's gangrene caused by Streptococcus dysgalactiae subsp. equisimilis (SDSE), a strain of pyogenic $\beta$-hemolytic streptococci that is increasingly being recognized as an important human pathogen.

Case presentation: We describe a healthy 59 year-old Caucasian male who presented to the emergency department with Fournier's gangrene of the penis and scrotum, with extension to the anterior abdominal wall. He underwent urgent surgical debridement of his scrotum, penis, and anterior abdomen. Swabs from the scrotum grew Gram-positive cocci, which were initially identified as Streptococcus anginosus group by matrix-assisted laser desorption ionization-time of flight mass spectrometry (MALDI-TOF MS). However, polymerase chain reaction (PCR) amplification and sequencing of the 16S rRNA gene identified the isolate as Streptococcus dysgalatiae subspecies equisimilis (SDSE). The incidences of invasive S. anginosus group and SDSE infections at the London Health Sciences Centre, a tertiary-care institution in southwestern Ontario, were determined between August 1, 2011 and August 31, 2012, revealing a slightly lower rate of SDSE (3.2 cases per 100,000 population) than other studies.

Conclusions: This case highlights a unique disease manifestation of the emerging human pathogen Streptococcus dysgalatiae subspecies equisimilis that has not been previously reported. This case also underscores the limitations of MALDI-TOF MS in differentiating between closely-related streptococcal species which may have different pathogenic profiles.
\end{abstract}

Keywords: Streptococcus dysgalactiae subsp. equisimilis, Fournier's gangrene, MALDI-TOF MS, Species identification

\section{Background}

Fournier's gangrene is a rare necrotizing infection of the male genitalia $[1,2]$. It is classically characterized by intense pain and tenderness in the genitals, rapidly progressing to gangrene and septic shock. Risk factors include diabetes [1], immune compromise, drug use, obesity, and trauma to the perineum [2,3]. Most cases of Fournier's gangrene are polymicrobial [2], and commonly isolated microorganisms include Escherichia,

\footnotetext{
* Correspondence: rananth@uwo.ca

${ }^{1}$ Western University, London, Ontario, Canada

'Department of Microbiology and Immunology, Siebens-Drake Research Institute Room 133, Western University, 1400 Western Road, London N6G 2V4, Canada
}

Klebsiella, Bacteroides, Clostridium, streptococci and enterococci [1]. Early therapy is critical, including surgical debridement, broad-spectrum antibiotics, and skin grafting [1-3]. We describe a case of Fournier's gangrene in a healthy male caused by Streptococcus dysgalactiae subsp. equisimilis (SDSE), initially misidentified as Streptococcus anginosus group. SDSE is a pyogenic $\beta$-hemolytic Streptococcus that is emerging as a human pathogen with a similar disease profile to $S$. pyogenes [4-6]. While it primarily presents as skin and soft-tissue infections, including cellulitis and necrotizing fasciitis [4], SDSE can also cause endocarditis, rheumatic fever, and streptococcal toxic shock-like syndrome $[5,6]$. With an ever-increasing clinical 
burden, there is a need to accurately identify invasive SDSE infections.

\section{Case presentation}

A 59 year-old, previously healthy Caucasian male presented with scrotal and penile pain for six days, and brownishblack discoloration of the scrotum. His past medical and surgical history was non-contributory and he did not take any medications. There was no history of trauma or sepsis in the genital area, and there were no symptoms of dysuria or hematuria. A review of systems was unremarkable. On examination, the patient was alert and oriented, but appeared unwell. He was also febrile $\left(38.3^{\circ} \mathrm{C}\right)$, tachycardic (heart rate $116 / \mathrm{min}$ ), and normotensive (blood pressure 136/79). His lower abdomen was erythematous with palpable subcutaneous emphysema extending to the umbilicus. His penile shaft was swollen and tender, and his scrotum was necrotic. Bloodwork revealed a white cell count of $17 \times 10^{9} / \mathrm{L}$, hyponatremia $(125 \mathrm{mmol} / \mathrm{L})$, hypochloremia $(86 \mathrm{mmol} / \mathrm{L})$, and elevated serum lactate $(3.1 \mathrm{mmol} / \mathrm{L})$. The patient's international normalized ratio (INR) was 1.6, and his serum alanine-aminotransferase (ALT), and serum aspartate-aminotransferase (AST) were elevated at $127 \mathrm{U} / \mathrm{L}$, and $66 \mathrm{U} / \mathrm{L}$ respectively. Blood glucose and serum creatinine were within normal limits.

Intravenous treatment with vancomycin $(1 \mathrm{~g}$ every $12 \mathrm{~h})$, and piperacillin-tazobactam $(4.5 \mathrm{~g}$ every $8 \mathrm{~h})$ was initiated. The patient was urgently taken to the operating room and underwent extensive debridement of his scrotum, penile shaft, and anterior abdomen, while preserving the testes and abdominal muscles. A small abscess cavity communicating with the necrotizing infection was identified in the right buttock and debrided. A suprapubic catheter was placed for urinary diversion, and the patient was admitted to the intensive care unit. After 48 hours, he underwent a transverse colostomy to divert stool from his perineum, and skin grafting to close his anterior abdominal wounds and penile shaft. His testes were tunnelled into his thighs, and after sixteen days in hospital, he was discharged home.

A swab from the scrotal tissue was taken during the initial operation, and was streaked on blood agar plates, resulting in a monoculture of uniformly-sized beta-haemolytic colonies. From this, the bacteria was isolated and subjected to matrix-assisted laser desorption ionization-time of flight mass spectrometry (MALDI-TOF MS) to identify the organism as Streptococcus anginosus group (score $=2.3$ ), although the software (Biotyper software version 3.0) was unable to distinguish the species. Susceptibility testing was performed by the Kirby-Bauer disc diffusion method [7], and the organism was sensitive to ceftriaxone, clindamycin, erythromycin, penicillin, and vancomycin. Polymerase chain reaction (PCR) amplification (Table 1) and sequencing of the $16 \mathrm{~S}$ rRNA amplicon from DNA isolated from overnight cultures of two isolated colonies identified the isolate as Streptococcus
Table 1 List of primers used to amplify streptococcal superantigen genes, 165 ribosomal RNA (rRNA), and emm genes

\begin{tabular}{|c|c|c|}
\hline Name & Sequence 5'-3' & Source \\
\hline SpeA forward & AAAGTTGCCATCTCTTGGTTC & Sigma genosys \\
\hline SpeA reverse & CAAGAGGTATITGCTCAACAAGAC & Sigma genosys \\
\hline SpeC forward & TाTGAGCAGGCGTAATTCCT & Sigma genosys \\
\hline SpeC reverse & TTCAACGACACACACATTAAACA & Sigma genosys \\
\hline SpeG forward & ACCCCATGCGATTATGAAAA & Sigma genosys \\
\hline SpeG reverse & GGGAGACCAAAAACATCGAC & Sigma genosys \\
\hline SpeH forward & ATTCCAATGTTGTTCAAGCAAA & Sigma genosys \\
\hline SpeH reverse & TGAGCGGTTACTTTCGGTIT & Sigma genosys \\
\hline Spel forward & TCCGCCATITTCAGGTAGTT & Sigma genosys \\
\hline Spel reverse & ПТССТТССТCAAAGCCAGA & Sigma genosys \\
\hline SpeJ forward & GCTCTCGACCTCAGAATCAA & Sigma genosys \\
\hline SpeJ reverse & СTाCATGGGTACGGAAGTG & Sigma genosys \\
\hline SpeK forward & CAAACAAGGAACGCAATTGAT & Sigma genosys \\
\hline SpeK reverse & GTGTCTAATGCCACCGTCT & Sigma genosys \\
\hline Spel forward & ATAAGTCAGCACCTTCCTCTITC & Sigma genosys \\
\hline Spel reverse & AAATCTCCCGTTACCTTCCA & Sigma genosys \\
\hline SpeM forward & AACTTCTTCTTCCTTAAAGCGTCT & Sigma genosys \\
\hline SpeM reverse & TGCTGTGTTGGTTAATAGCGA & Sigma genosys \\
\hline SmeZ forward & TICTCGTCCTGTGATTGGA & Sigma genosys \\
\hline SmeZ reverse & AATGGGACGGAGAACATAGC & Sigma genosys \\
\hline SSA forward & ACAGGTCAGCTITACAGCA & Sigma genosys \\
\hline SSA reverse & GGGCATCATATCGTACCAAA & Sigma genosys \\
\hline $16 \mathrm{~S}$ rRNA forward & AGAGTTTGATCCTGGCTCAG & $\begin{array}{l}\text { Invitrogen life } \\
\text { technologies }\end{array}$ \\
\hline $16 \mathrm{~S}$ rRNA reverse & AAGGAGGTGATCCAGCCGCA & $\begin{array}{l}\text { Invitrogen life } \\
\text { technologies }\end{array}$ \\
\hline $\begin{array}{l}\text { emm genotyping } \\
\text { primer forward }\end{array}$ & TATTCGCTTAGAAAATTAA & $\begin{array}{l}\text { Invitrogen life } \\
\text { technologies }\end{array}$ \\
\hline $\begin{array}{l}\text { emm genotyping } \\
\text { primer reverse }\end{array}$ & GCAAGTTCTCAGCTTGTT & $\begin{array}{l}\text { Invitrogen life } \\
\text { technologies }\end{array}$ \\
\hline
\end{tabular}

dysgalatiae subspecies equisimilis. This was further confirmed by sequencing the emm amplicon and performing a BLAST search on the Centers for Disease Control (CDC) streptococcal $\mathrm{emm}$ sequence database [8]: the isolate was identified as group G Streptococcus emm type stG643.0. Further PCR amplification experiments (Additional file 1: Figure S1) did not detect any of the 11 known streptococcal superantigen genes [9], when compared to genomic DNA preparations of S. pyogenes serotypes MGAS5005 [9], SF370 [10], MGAS8232 [10], and MGAS315 [10], which served as positive controls. In addition, proliferation assays [11] confirmed the absence of Group A streptococcal superantigen activity in the isolate (Addition file 1: Figure S2). Briefly, supernatants from overnight cultures of the isolate were added to fresh, gradient-purified human peripheral blood 
mononuclear cells (PBMCs; $2.0 \times 10^{5}$ cells/well) in 96-well plates. After 3 days, ${ }^{3} \mathrm{H}$-thymidine was added for $18 \mathrm{~h}$ to measure proliferation. Supernatant from $S$. pyogenes strain MGAS5005 [9] served as a positive control.

We also used the London Health Sciences Centre (LHSC) microbiology database to retrospectively review patients with invasive $S$. anginosus group or SDSE infections at LHSC (a tertiary-care centre in Southwestern Ontario that serves a regional population of 435000 ) between August 1, 2011 and August 31, 2012. The review was conducted according to the Helsinki Declaration, and approved by the Research Ethics Board of Western University (approval number 103036). Incidences were calculated using Statistics Canada census data from 2011 [12]. We identified 17 cases of invasive S. anginosus group infections (3.9 cases per 100,000 population), and 14 cases of invasive SDSE infections (3.2 cases per 100,000 population; Table 2). When testing antibiotic susceptibility by the disc diffusion method [7], all SDSE isolates were sensitive to penicillin, whereas $6 \%$ of $S$. anginosus group isolates were resistant. Two SDSE isolates (14\%) were resistant to clindamycin and one (7\%) was resistant to erythromycin (Table 2).

\section{Conclusions}

Fournier's gangrene was first identified in 1883, when the French dermatologist and venereologist Jean Alfred Fournier diagnosed a rapidly progressive gangrene of the genitalia with no discernible etiology in five young men [13]. Now defined as a necrotizing fasciitis of the perineal or genital areas [1,2], Fournier's gangrene remains unusually rare, with an incidence ranging from $0.002 \%$ to $0.005 \%$ of annual hospital admissions [14]. The infection can rapidly spread throughout the perineum, thighs, and torso, subsequently leading to gangrene, septic

Table 2 Characteristics of invasive SDSE and S. anginosus group infections in a one-year period at London health sciences centre

\begin{tabular}{lcc}
\hline Characteristics & SDSE & S. anginosus group \\
\hline Patients, $\mathrm{n}$ & 14 & 17 \\
Rate (per 100,000 population) & 3.2 & 3.9 \\
Source of organism, $\mathrm{n}(\%)$ & & $6(35)$ \\
Blood & $11(79)$ & $10(59)$ \\
Tissue & $3(21)$ & $1(6)$ \\
Cerebrospinal fluid (CSF) & $0(0)$ & \\
Antibiotic resistance, $\mathrm{n}(\%)$ & & $1(6)$ \\
Penicillin & $0(0)$ & $1(6)$ \\
Ceftriaxone & - & $2(12)$ \\
Erythromycin & $1(7)$ & $2(12)$ \\
Clindamycin & $2(14)$ & $0(0)$ \\
Vancomycin & - &
\end{tabular}

shock, and death if untreated. Although Group A streptococci were thought to be the sole cause of Fournier's gangrene [15], subsequent clinical series have emphasized the polymicrobial nature of the disease $[1,16]$, which is hypothesized to synergize enzyme production and promote rapid multiplication and spread of infection [1]. The most common causative microorganisms include facultative organisms (E. coli, Klebsiella, enterococci), along with anaerobes (Bacteroides, Fusobacterium, Clostridium, or anaerobic or microaerophilic Streptococci). This case is unique because the patient lacked the typical risk factors associated with Fournier's gangrene, such as diabetes, immune compromise, obesity, drug use, or genital trauma [1-3], and his infection was caused by Streptococcus dysgalactiae subsp. equisimilis (SDSE).

SDSE, a pyogenic $\beta$-hemolytic streptococcus [17], usually colonizes the upper respiratory, gastrointestinal, and female genital tracts [17]. However, it is increasingly being recognized as an important human pathogen [18], with a wide spectrum of disease similar to that caused by $S$. pyogenes [5], including endocarditis, rheumatic fever, and streptococcal toxic shock-like syndrome [6]. In a recent population-based study, the burden of invasive SDSE infections approximated that of invasive $S$. pyogenes infections [4]. SDSE primarily presents as skin and soft-tissue infections, including pyoderma, cellulitis, wound infections, abscesses, erysipelas, and necrotizing fasciitis [4]. SDSE contains either Lancefield group antigens $\mathrm{C}$ or $\mathrm{G}$, but needs to be distinguished from $S$. anginosus group strains, which frequently contain the same antigens. The use of MALDI-TOF MS to differentiate between streptococcal species has been established [19-21], although misidentification may occur because of striking similarities in proteomic profiles [22,23]. The organism in our case was misidentified as $S$. anginosus group by MALDI-TOF MS, because sequencing the $16 \mathrm{~S}$ rRNA segment confirmed the isolate as SDSE. While few laboratories report identification of $\beta$-hemolytic Group C and G streptococci to the species level [24], differentiation should not be ignored because SDSE is more invasive than the S. anginosus group [25], and may have virulence factors similar to $S$. pyogenes [26,27]. Although the presence of streptococcal superantigens such as SpeG homologues have been described in SDSE $[6,28]$, our clinical isolate lacked Group A streptococcal superantigen genes and activity. Nevertheless, our case demonstrates the potential benefit of molecular assays in differentiating closely-related streptococcal species, although further studies are needed to assess their clinical impact. To our knowledge, there are no other reports of Fournier's gangrene caused by Streptococcus dysgalactiae subspecies equisimils (SDSE). One study isolated Group C Streptococcus from the perineum of a diabetic male 
with Fournier's gangrene [29], but the species was not reported, and a potential role for superantigens was not investigated.

At our institution, the incidences of invasive $S$. anginosus group and SDSE infections were 3.9 and 3.2 cases per 100,000 respectively (Table 2). The rate of invasive $S$. anginosus group infection is slightly higher than previous studies [4], while the rate of invasive SDSE infection is slightly lower. Although rare penicillin-resistant SDSE strains have been reported [30], isolates from our centre were sensitive to penicillin. Six percent of $S$. anginosus group isolates, however, were resistant to penicillin, which is higher than other studies [31]. While the mechanisms of resistance have yet to be fully elucidated, the potential transfer of penicillin resistance determinants from related Streptococcal species [32], together with selective antibiotic pressure, may play a role in the emergence of penicillin resistance in the $S$. anginosus group [4,33]. Therefore, the addition of an aminoglycoside to a cell wall-active agent may be appropriate for severe $S$. anginosus group infections to avoid delayed response of infection [33]. Similar to other studies [30] showing widespread resistance to macrolides (16-24\%) we also observed erythromycin resistance $(12 \%$ and 7\% for S. anginosus group and SDSE isolates, respectively), albeit at a lower rate. Additionally, $12 \%$ of $S$. anginosus group isolates and 14\% of SDSE isolates were resistant to clindamycin, suggesting that despite the popularity of macrolide and clindamycin use in infected patients, they may not be appropriate for all cases.

In conclusion, we present a case of Fournier's gangrene of the penis caused by SDSE, highlighting a unique disease presentation of the organism, and underscoring the limitations of MALDI-TOF MS in differentiating between closely-related streptococcal species which may hixave differing pathogenic profiles.

\section{Consent}

Written informed consent was obtained from the patient for publication of this case report. A copy of the written consent is available for review by the editor of this journal.

\section{Additional file}

Additional file 1: Figure S1. PCR analysis of $\mathrm{S}$. dysgalactiae subspecies equisimilis (SDSE) chromosomal DNA did not detect any known Group A streptococcal superantigen genes. S. dysgalactiae subspecies equisimilis (s), positive control (S. pyogenes MGAS5005, SF370, MGAS8232, and MGAS315; +), and negative control (no template). Figure S2: Supernatant from the clinical isolate identified as $\mathrm{S}$. dysgalactiae subspecies equisimilis (SDSE) failed to induce the proliferation of human PBMCs. Human PBMCs were incubated with supernatant dilutions from $\mathrm{S}$. pyogenes strain MGAS5005 or the clinical isolate for $72 \mathrm{~h}$ and subsequently pulsed with [3H]thymidine to assess mitogenic activity. DNA was harvested after $18 \mathrm{~h}$, and the counts per minute (cpm) were determined by scintillation counting and normalized. The mean ( \pm SEM) of experiments performed in quadruplicate are shown.
Competing interests

The authors report no actual or potential conflicts of interest.

\section{Authors' contributions}

RVA collected the tissue culture sample, contributed to the discussion of the results, and drafted and wrote the manuscript. KJK carried out the PCR amplification of the 16S rRNA and superantigen genes and contributed to the discussion of the results. KGP performed the proliferation assay and generated the supplementary figures. JJZ carried out the emm sequencing. JD and JKM contributed to the assessment and discussion of the results. All authors read and approved the final manuscript.

\section{Acknowledgements}

This study was funded by the Division of General Surgery, Western University, and the Canadian Institutes of Health Research (CIHR) operating grant MOP-64176.

Received: 11 March 2013 Accepted: 19 August 2013

Published: 20 August 2013

\section{References}

1. Rudolph R, Soloway M, DePalma RG, Persky L: Fournier's syndrome: synergistic gangrene of the scrotum. Am J Surg 1975, 129(5):591-596.

2. Yumura Y, Chiba K, Saito K, Hirokawa M: Fournier's gangrene of penis in a patient with malignant lymphoma: a case report. Hinyokika Kiyo 2000, 46:735-737.

3. Schneider PR, Russell RC, Zook EG: Fournier's gangrene of penis: a report of two cases. Ann Plast Surg 1986, 17:87-90.

4. Broyles LN, Van Beneden C, Beall B, Facklam R, Shewmaker PL, Malpiedi P, Daily P, Reingold A, Farley MM: Population-based study of invasive disease Due to $\beta$-hemolytic streptococci of groups other than a and $B$. Clin Infect Dis 2009, 48(6):706-712.

5. Efstratiou A: Pyogenic streptococci of lancefield groups $C$ and $G$ as pathogens in man. Soc Appl Bacteriol Symp Ser 1997, 26:72S-79S.

6. Hashikawa S, linuma Y, Furushita M, Ohkura T, Nada T, Torii K, Hasegawa T, Ohta M: Characterization of group $C$ and $G$ streptococcal strains that cause streptococcal toxic shock syndrome. J Clin Microbio/ 2004, 42(1):186-192.

7. Clinical and Laboratory Standards Institute: Performance standards for antimicrobial disk susceptibility tests. Approved standard M2-A10. Wayne, PA: Clinical and Laboratory Standards Institute; 2009.

8. Streptococci Group A Subtyping Request Form Blast 2.0 Server. [http://www. cdc.gov/ncidod/biotech/strep/strepblast.htm]

9. Brouillard JN, Gunther S, Varma AK, Gryski I, Herfst CA, Rahman AK, Leung DY, Schlievert PM, Madrenas J, Sundberg EJ, et al: Crystal structure of the streptococcal superantigen Spel and functional role of a novel loop domain in T cell activation by group V superantigens. J Mol Biol 2007, 367(4):925-934.

10. Beres SB, Sylva GL, Barbian KD, Lei B, Hoff JS, Mammarella ND, Liu MY, Smoot JC, Porcella SF, Parkins LD, et al: Genome sequence of a serotype M3 strain of group A Streptococcus: phage-encoded toxins, the highvirulence phenotype, and clone emergence. Proc Natl Acad Sci U S A 2002, 99(15):10078-10083.

11. Li Y, Li H, Dimasi N, McCormick JK, Martin R, Schuck P, Schlievert PM, Mariuzza RA: Crystal structure of a superantigen bound to the high-affinity, zinc-dependent site on MHC class II. Immunity 2001, 14(1):93-104.

12. Census Profile - Population Centre. [http://www12.statcan.gc.ca/censusrecensement/2011/dp-pd/prof/details/page.cfm?Lang=E\&Geo1=POPC\& Code $1=0480 \&$ Geo $2=$ PR\&Code $2=35 \&$ Data $=$ Count $\&$ SearchText $=$ London $\&$ SearchType $=$ Begins \&SearchPR=01\&B1=All\&Custom $=\& T A B I D=1]$

13. Fournier JA: Gangrene foudroyante de la verge. Semaine Médicale 1883, 4:589-597.

14. Sorensen MD, Krieger JN, Rivara FP, Broghammer JA, Klein MB, Mack CD, Wessells H: Fournier's gangrene: population based epidemiology and outcomes. J Urol 2009, 181(5):2120-2126.

15. Meleney FL, Zau ZD: The viability of hemolytic streptococcus in certain solutions containing gelatin. J Exp Med 1924, 39(6):811-825.

16. Bernstein SM, Celano T, Sibulkin D: Fournier's gangrene of penis. South Med J 1976, 69:1242-1244.

17. Vandamme PPB, Falsen E, Kersters $K$, Devriese LA: Taxonomic study of Lancefield streptococcal groups C, G, and L (Streptococcus dysgalactiae) 
and proposal of S. dysgalactiae subsp. equisimilis subsp. nov. Int J Syst Bacteriol 1996, 46:774-781.

18. Barnham MR, Weightman NC: Changing incidence of detected streptococcal bacteraemia in North Yorkshire, England. Indian J Med Res 2004, 119(S):160-163.

19. Risch M, Radjenovic D, Han JN, Wydler M, Nydegger U, Risch L: Comparison of MALDI TOF with conventional identification of clinically relevant bacteria. Swiss Med Wkly 2010, 140:w13095.

20. Eigner U, Holfelder M, Oberdorfer K, Betz-Wild U, Bertsch D, Fahr AM: Performance of a matrix-assisted laser desorption ionization-time-of-flight mass spectrometry system for the identification of bacterial isolates in the clinical routine laboratory. Clin Lab 2009, 55(7-8):289-296.

21. Cherkaoui A, Emonet S, Fernandez J, Schorderet D, Schrenzel J: Evaluation of matrix-assisted laser desorption ionization-time of flight mass spectrometry for rapid identification of Beta-hemolytic streptococci. J Clin Microbiol 2011, 49(8):3004-3005.

22. Seng $P$, Drancourt M, Gouriet F, La Scola B, Fournier PE, Rolain JM, Raoult D: Ongoing revolution in bacteriology: routine identification of bacteria by matrix-assisted laser desorption ionization time-of-flight mass spectrometry. Clin Infect Dis 2009, 49(4):543-551.

23. Stevenson LG, Drake SK, Murray PR: Rapid identification of bacteria in positive blood culture broths by matrix-assisted laser desorption ionization-time of flight mass spectrometry. J Clin Microbiol 2010, 48(2):444-447.

24. Facklam R: What happened to the streptococci: overview of taxonomic and nomenclature changes. Clin Microbiol Rev 2002, 15:613-630.

25. Cimolai N, MacCulloch L, Damm S: The epidemiology of beta-haemolytic non-group A streptococci isolated from the throats of children over a one-year period. Epidemiol Infect 1990, 104(1):119-126.

26. Igwe El, Shewmaker PL, Facklam RR, Farley MM, van Beneden C, Beall B: Identification of superantigen genes speM, ssa, and smeZ in invasive strains of beta-hemolytic group C and G streptococci recovered from humans. FEMS Microbiol Lett 2003, 229(2):259-264.

27. Schnitzler N, Podbielski A, Baumgarten G, Mignon M, Kaufhold A: M or $\mathrm{M}$-like protein gene polymorphisms in human group $\mathrm{G}$ streptococci. J Clin Microbiol 1995, 33(2):356-363.

28. Sachse S, Seidel P, Gerlach D, Gunther E, Rodel J, Straube E, Schmidt KH: Superantigen-like gene(s) in human pathogenic Streptococcus dysgalactiae, subsp equisimilis: genomic localisation of the gene encoding streptococcal pyrogenic exotoxin G (speG(dys)). FEMS Immunol Med Microbiol 2002, 34(2):159-167.

29. Marinella MA: Group C streptococcal sepsis complicating Fournier gangrene. South Med J 2005, 98(9):921-923.

30. Biedenbach DJ, Toleman MA, Walsh TR, Jones RN: Characterization of fluoroquinolone-resistant beta-hemolytic Streptococcus spp. isolated in North America and Europe including the first report of fluoroquinolone-resistant Streptococcus dysgalactiae subspecies equisimilis: report from the SENTRY Antimicrobial Surveillance Program (1997-2004). Diagn Microbiol Infect Dis 2006, 55(2):119-127.

31. Tracy M, Wanahita A, Shuhatovich Y, Goldsmith EA, Clarridge JE 3rd, Musher DM: Antibiotic susceptibilities of genetically characterized Streptococcus milleri group strains. Antimicrob Agents Chemother 2001, 45(5):1511-1514.

32. Dowson CG, Hutchison A, Woodford N, Johnson AP, George RC, Spratt BG: Penicillin-resistant viridans streptococci have obtained altered penicillinbinding protein genes from penicillin-resistant strains of Streptococcus pneumoniae. Proc Natl Acad Sci U S A 1990, 87(15):5858-5862.

33. Brandt CM, Spellerberg B: Human infections due to Streptococcus dysgalactiae subspecies equisimilis. Clin Infect Dis 2009, 49(5):766-772

doi:10.1186/1471-2334-13-381

Cite this article as: Anantha et al:: Fournier's gangrene of the penis caused by Streptococcus dysgalactiae subspecies equisimilis: case report and incidence study in a tertiary-care hospital. BMC Infectious Diseases 2013 13:381.

\section{Submit your next manuscript to BioMed Central and take full advantage of:}

- Convenient online submission

- Thorough peer review

- No space constraints or color figure charges

- Immediate publication on acceptance

- Inclusion in PubMed, CAS, Scopus and Google Scholar

- Research which is freely available for redistribution

Submit your manuscript at www.biomedcentral.com/submit
C Biomed Central 